\title{
Cruciform specimens' experimental analysis in ultrasonic fatigue testing
}

\section{Authors}

P. R. Costa ${ }^{1}$, D. Montalvão ${ }^{2}$, M. Freitas ${ }^{3}$, R. Baxter $^{4}$, L. Reis ${ }^{3 *}$

${ }^{1}$ Instituto Superior Técnico, Universidade de Lisboa, Av. Rovisco Pais, 1, 1049-001 Lisbon, Portugal

${ }^{2}$ Department of Design and Engineering, Faculty of Science and Technology, Bournemouth University, Poole House, Talbot Campus, Fern Barrow, Poole BH12 5BB, UK

${ }^{3}$ IDMEC, Instituto Superior Técnico, Universidade de Lisboa, Av. Rovisco Pais, 1, 1049-001 Lisbon, Portugal

${ }^{4}$ School of Engineering and Technology, University of Hertfordshire, College Lane Campus, Hatfield AL10 9AB, UK

\begin{abstract}
In this work, two special aluminium cruciform specimens are designed and tested in an ultrasonic fatigue machine. They were designed based on Single-Input-Multiple-Output (SIMO) modal analysis to induce in-plane biaxial stress combinations (in-phase T-T and outof-phase $\mathrm{C}-\mathrm{T}$ ) when at resonance at $20 \mathrm{kHz}$. The geometries were subjected to both numerical analysis and experimental testing to understand if they can indeed create the intended biaxial state of stresses. Both numerical and experimental results showed an impact of nearby resonant modes of non-interest on the correct functioning of the specimens, especially regarding the T-T specimen where a large deviation from the mode of interest was measured. This means that future work includes re-designing T-T specimens taking into account these mode shapes. Only out-of-phase specimens demonstrated to work properly and tests until failure were conducted. The first failure results showed to be consistent with literature when out-of-phase biaxial stress is applied cyclically.
\end{abstract}

\section{Keywords}

Cruciform specimens; Biaxial stresses; axial-axial; Ultrasonic fatigue; VHCF

\section{Nomenclature}

$f$, frequency;

$\mathbf{R}$, stress ratio; 
L, D, RM, Rm, dd, t, tt, w, $\boldsymbol{\theta}$, specimen dimension designations;

U, displacement;

$\sigma$, stress;

$B$, biaxial ratio;

\section{Introduction}

The study of material damage in dynamic systems or structures is necessary to ensure their safety and reliability since fatigue is one of the main causes of material failure ${ }^{1}$. For example, on a study of a failed crankshaft subjected to dynamic loads ${ }^{2}$, it is shown how important it is to understand the reasons behind fatigue failure so that preventive measures can be taken in the future. With the evolution of technology, systems and machines have become more and more complex. At the same time, there is a demand to achieve greater performances with increased reliability; hence, more thorough fatigue studies are required for higher number of cycles and different load types and combinations.

Since the realisation that the fatigue limit in the classical sense is no longer applicable 3,4 , the corresponding fatigue regime needs to be fully comprehended and characterised. This corresponds to life beyond $10^{7}$ cycles, the Very High Cycle Fatigue (VHCF) regime.

Conventional fatigue testing methods usually apply the stress cycle in a low frequency setting. Even with a machine operating at $100 \mathrm{~Hz}$ frequency the time required to study a certain material in the VHCF regime will be unfeasible and energy-wise very consuming. For example, if one would want to achieve $10^{9}$ cycles at $100 \mathrm{~Hz}$, a single test would take around 4 months to complete, whereas in ultrasonic fatigue testing at $20 \mathrm{kHz}$ this time could be reduced, in principle, to less than one day, if no interruptions had to be made.

Because conventional fatigue machines would take an unfeasible amount of time to achieve cycles between $10^{6}$ and $10^{9}$ (VHCF regime) a new type of machine was developed capable of inducing high frequency cycles: the ultrasonic fatigue testing machine. Mason in 1950 was the first to build such machine successfully establishing the standard frequency of $20 \mathrm{kHz}{ }^{4}$. In ultrasonic testing, the components' set is excited in resonance in order to apply 
high stresses at high frequencies. All the parts are designed to have the resonant mode of interest tuned to the working frequency of the actuator (typically, a piezoelectric transducer). The specimen is then excited at a specific resonant mode that induces higher stresses within a well-determined section of the specimen for the fatigue study.

The first studies with ultrasonic fatigue machines applied uniaxial tension/compression (stress ratio $R=-1$ ) using a booster and horn to amplify the displacements introduced by the transducer. Many different materials have been tested, such as alloy steels ${ }^{5}$, aluminium ${ }^{6,7}$ and copper ${ }^{8}$. Also, several variants of the test where different parameters are controlled and analysed ${ }^{9}$, like corrosion ${ }^{10}$ and fretting ${ }^{11}$, were conducted.

With the development of ultrasonic fatigue testing many new trends capable of applying different stress combinations than the first uniaxial tension/compression were created, like uniaxial bending ${ }^{12}$ and biaxial bending ${ }^{13}$, torsion ${ }^{5,14}$, or even combined multiaxial tension/compression with torsion ${ }^{15,16}$. All the aforementioned ultrasonic fatigue tests are based on the same principles: the specimens are designed so that they resonate at the machine's operating frequency (typically $20 \mathrm{kHz}$ ) with mode shapes that induce welldetermined stresses at a well-determined location of the specimen where the nucleation of fatigue cracks will occur.

In this work, ultrasonic fatigue tests were conducted to analyse cruciform test specimens that were purposely designed to induce an orthogonal biaxial state of stress at its centre when resonating at $20 \mathrm{kHz}$, as initially proposed by Montalvão and Wren ${ }^{17}$. The designs for VHCF are based on other cruciform specimens that have been created and optimised by several authors for the study of fatigue for this type of complex biaxial stress cycle in conventional non-ultrasonic machines ${ }^{18-21}$. Two cruciform geometries were tested, one with in-phase tension-tension biaxial stresses (T-T) and the second with out-of-phase tension-compression biaxial stresses (C-T). A uniaxial ultrasonic fatigue testing machine with a single actuator operating at $20 \mathrm{kHz}$ coupled with a booster and a horn was used to excite one of the cruciform specimens' resonant mode shapes (T-T or C-T) at a single coordinate (an anti-node) with a point load. Since the specimens are cruciform, it will be shown that a biaxial state of stress is induced at the centre of the specimen even if only one actuator is used. 


\section{Theoretical background and Methodology}

As it was mentioned above, two types of cruciform specimens were designed, numerically analysed, manufactured and tested, based on the designs from ${ }^{21,22}$, and were adapted following the guidelines from ${ }^{17}$, so that they could be tested under ultrasonic fatigue loads in the uniaxial tension-compression test machine developed at Instituto Superior Técnico (University of Lisbon) ${ }^{23}$. The specimens have a cruciform shape, and both induce inplane axial-axial stress combinations, although in one design the stresses are in-phase (tension-tension or T-T) while in the other one they are out-of-phase (tension-compression or C-T). This specific geometrical shape is already in use in the conventional way of applying loads with four actuators ${ }^{24}$.

For the transformation from the conventional to the ultrasonic fatigue testing the base geometry shape form is kept, but the dimensions are changed so that the specimens have a specific resonant mode of interest around the working frequency of $20 \mathrm{kHz}$. The dimensions are dependent on the material of choice and the resonant mode of interest; thus, two geometries are created for tension-tension (T-T) and compression-tension (C-T) stress induced combinations. The analysed and tested geometries were obtained based on one of the co-authors previous work and experience ${ }^{17}$.

The two types of cruciform specimens in this study are excited in two different resonant modes. Both specimens follow a certain geometry with special relations between the dimensions. These relations were obtained from an optimisation of the geometry proposed by ${ }^{22}$. The geometry follows the design in Figure 1 with dimensions given by equations (1) to (6).

$$
\begin{aligned}
& R M(t)=-0.0379 t^{4}+0.8223 t^{3}-5.5749 t^{2}+12.555 t+53.84 \\
& R m(t)=-0.0236 t^{3}+0.3501 t^{2}-0.5036 t+22.184 \\
& d d(t)=-0.021 t^{4}+0.4668 t^{3}-3.248 t^{2}+7.9452 t+46.224 \\
& D(t)=0.0342 t^{3}-0.7936 t^{2}+6.0398 t+4.5526 .4 ; 4 \leq t \leq 10 \mathrm{~mm} \\
& \theta(t)=-0.7621 t^{3}+15.484 t^{2}-92.774 t+211.78 ; 4 \leq t \leq 10 \mathrm{~mm} \\
& t t(t)=0.15 t ; t \geq 8 \mathrm{~mm}
\end{aligned}
$$



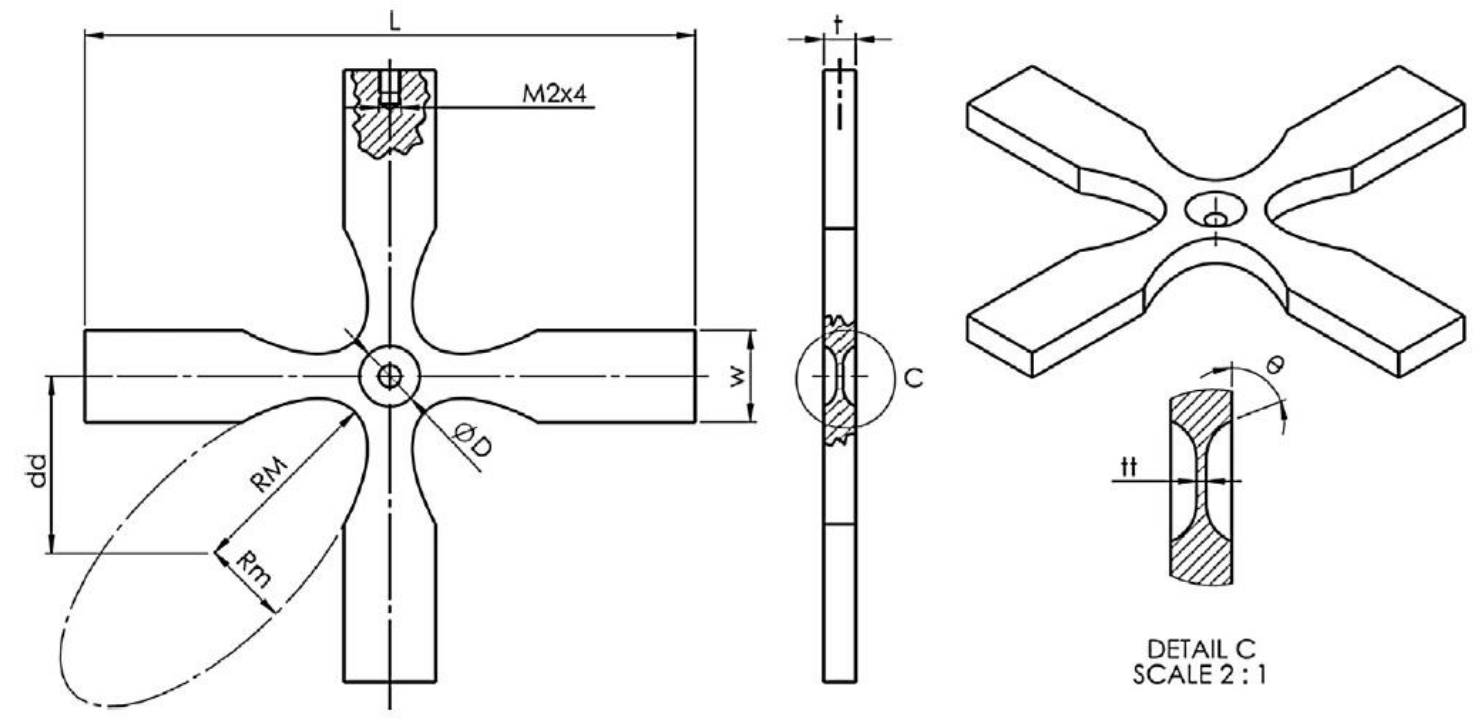

Fig. 1: Technical drawing of the cruciform specimen and designations of each dimension variation ${ }^{17,22}$.

To achieve a working specimen, i.e. one that has the intended in-phase or out-ofphase mode shape tuned at $20 \mathrm{kHz}$, the method described in ${ }^{17}$, that makes use of equations (1) to (6) and the application of a dimensional tuning scale factor, is followed. Therefore, the specimens used in this paper have the same dimensions as the ones proposed in ${ }^{17}$ (table 1 ).

Table 1: Dimensions and estimated mode frequencies of the ultrasonic specimens ${ }^{17}$.

\begin{tabular}{cccc}
\hline & $\begin{array}{c}\text { Original Design from } \\
22(t=10 \mathrm{~mm})\end{array}$ & $\begin{array}{c}\text { Ultrasonic Design } \\
(\mathrm{C}-\mathrm{T}) \text { from }^{17}\end{array}$ & $\begin{array}{c}\text { Ultrasonic Design } \\
(\mathrm{T}-\mathrm{T}) \text { from }{ }^{17}\end{array}$ \\
\hline scale & 1 & 0.4577 & 0.5533 \\
factor & & & \\
& & & 110.7 \\
$L(\mathrm{~mm})$ & 200 & 91.5 & 16.6 \\
$w(\mathrm{~mm})$ & 30 & 13.7 & 5.53 \\
$t(\mathrm{~mm})$ & 10 & 4.58 & 36.1 \\
$R M(\mathrm{~mm})$ & 65.2 & 29.8 & 16.0 \\
$R m(\mathrm{~mm})$ & 28.9 & 13.2 &
\end{tabular}




$\begin{array}{cccc}d d(\mathrm{~mm}) & 57.7 & 26.4 & 31.9 \\ D(\mathrm{~mm}) & 19.7 & 9.02 & 10.9 \\ t t(\mathrm{~mm}) & 1.50 & 0.687 & 0.830 \\ \theta\left(^{\circ}\right) & 70.6 & 70.6 & 70.6 \\ & & & \\ f(\mathrm{~Hz}) & 9,151 \mathrm{~Hz}(\mathrm{C}-\mathrm{T}) & 19,999 \mathrm{~Hz} & 20,000 \mathrm{~Hz}\end{array}$

A representation of the mode shapes' deformation is determined using Abaqus software and shown in Figure 2.

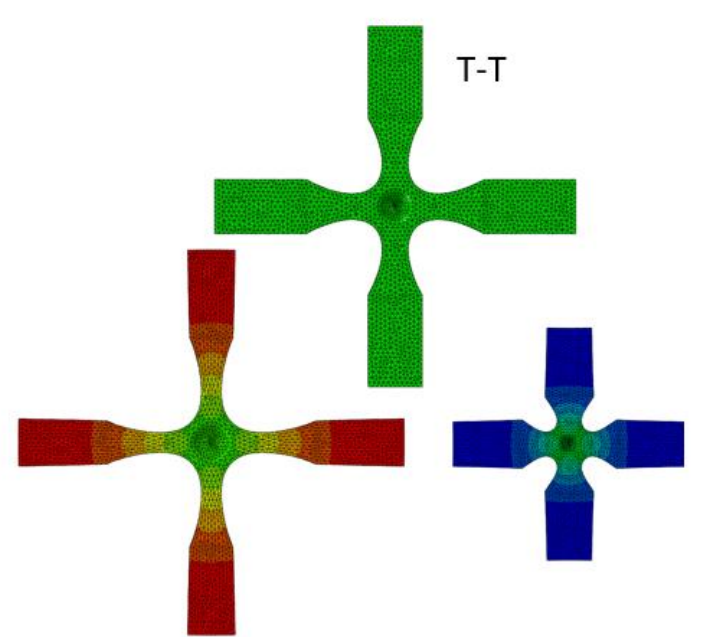

(A)

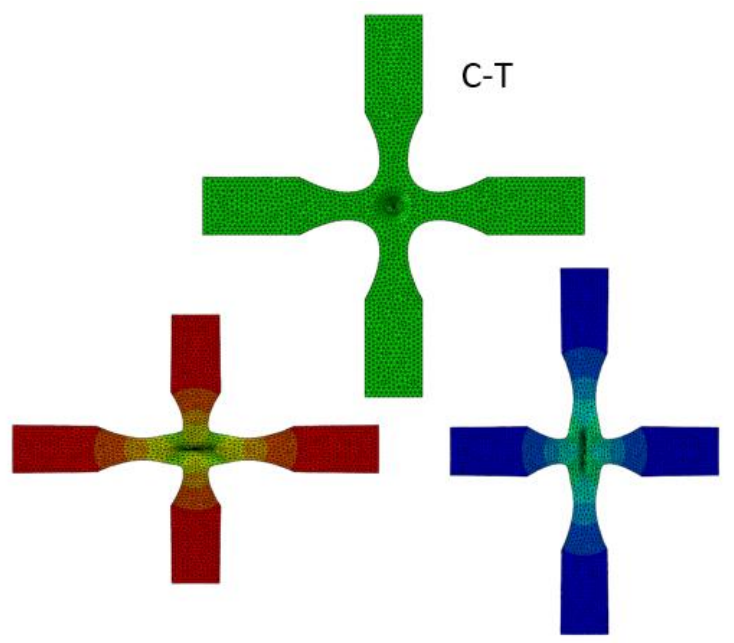

(B)

Fig. 2: Representation of the displacements of the resonant mode shapes of interest: $(A)$ inphase T-T; (B) out-of-phase C-T.

The material chosen was the 6082-T651 Aluminium alloy, a medium strength alloy used in a diverse range of applications, including highly stressed structures that are subjected to in-plane multiaxial loads. The material properties used in the finite element models are presented in Table 2.

Table 2: 6082-T651 Aluminium alloy properties.

\begin{tabular}{|l|l|l|}
\hline Density $\left(\mathrm{g} / \mathrm{cm}^{\wedge} 3\right)$ & Young Modulus (MPa) & Poisson's coefficient \\
\hline 2.70 & 70.000 & 0.33 \\
\hline
\end{tabular}


In both specimens there is one displacement node at the centre and stress nodes at the four extremities (i.e., where the stresses are null). Conversely, they both have two stress anti-nodes at the centre (i.e., where the stresses are maximum in both orthogonal directions) and displacement anti-nodes at the four extremities (i.e., where the displacements are maximum). The specimens are attached to the machine, composed by horn, booster and transducer, at only one of the specimen's extremities. The used machine was built at Instituto Superior Técnico laboratories in Lisbon as described in ${ }^{23}$ and ${ }^{25}$. The system's component's set is represented in Figure 3.

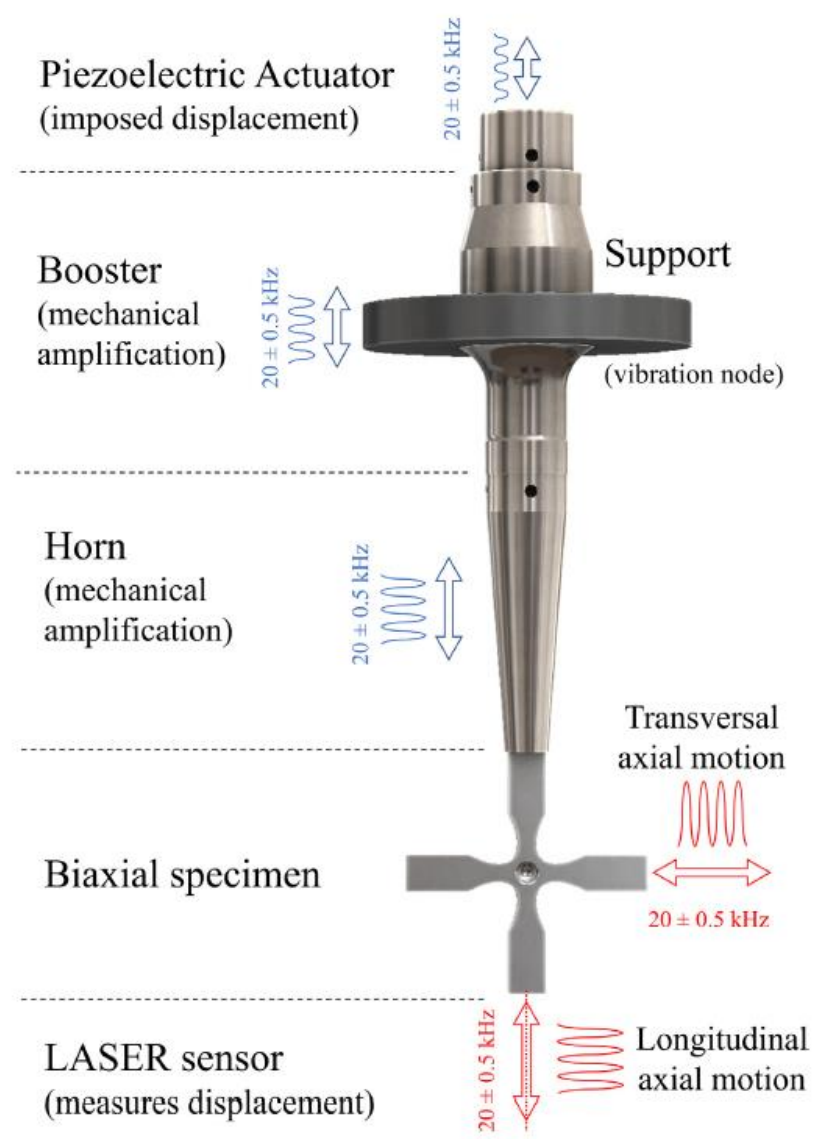

Fig. 3: Ultrasonic fatigue machine system components with cruciform specimen under test 17.

Longitudinal displacements with a frequency of around $20 \mathrm{kHz}( \pm 0.5 \mathrm{kHz})$ provided by the piezoelectric transducer are amplified by the booster and the horn and transmitted to 
the cruciform specimens. The movement transmitted by the horn excites the specimen in a specific resonant mode shape of interest for the biaxial fatigue study.

Several analyses were conducted in the finite element software. First, the resonant mode of each specimen was studied individually (because the nature of operation of ultrasonic fatigue testing machines is that they seek to reproduce free vibration with the specimen vibrating at its own natural frequency). Then, the horn and booster were included in the simulations to account for their influence which will show up due to the existence of a connection coordinate and frequency differences in all individual modes. These analyses helped to comprehend how the functioning geometry could be improved, based on the understanding on what other behaviours may be occurring beyond the pretended (and predicted) deformation. The results were compared qualitatively with the experimental analysis made afterwards.

Before performing any experimental test, a frequency analysis of the component set (booster; horn; specimen) with each of the machined specimens was made using the transducer's software. This analysis helped to firstly understand if it was possible to excite the produced specimens under resonance at the $20 \mathrm{kHz}( \pm 0.5 \mathrm{kHz})$ design frequency. It also provides the frequency of work. This frequency varies between each specimen tested and gives an insight of the deviation of the specimen frequency comparing it to the working frequency without the specimen. Simulations on FEA show that the resonant mode's frequency of the specimens have shown to be sensible to small geometrical variations.

Both T-T and C-T specimen's dynamic behaviours were afterwards analysed using a two-channel Polytec Laser Doppler Vibrometer (LDV) measuring axially (at the extremities of the arms) and transversely (along the longitudinal length of the arms) in pairs. The difference in amplitude and phase between two lasers measurements in certain key points of the cruciform specimens helps to understand if the specimen's mode shape is as predicted. Three different measurements were put in place: between the extremities (horizontal and vertical arm's); horizontal movement of vertical arms; vertical movement of horizontal arms and the variation along their length.

The measurements at the extremities help to understand if each specimen is inducing the displacement of the arms as intended and therefore the induced stress ratio at the centre. 
For the remaining tests, by measuring with the laser vibrometer transversally along the length of the arms we can perceive if the displacement has any discrepancies between the true and predicted motion. For the measurements to be made laser reflectors were glued to the specimen's arms at all the measurement points of interest.

The material's hysteretic damping is responsible for the generation of heat during tests ${ }^{26}$; this means that where the material is deforming the most (in the sense of strain; hence where the highest stress is) the heat generated is the highest. With the use of a thermal camera, all specimens were observed to view if the centre showed the generation of heat, since that is the expected area of highest stress. To obtain the thermal response on the camera the specimen's side on film was painted matte-black beforehand.

After analysing all machined geometries of both shapes, the specimens that showed best agreement between the Finite Element Models and experimental results were tested to failure. All the experimental tests followed a similar methodology to the one described in 25 with temperature control.

\section{Results and discussion}

\subsection{Finite element analysis (FEA)}

The two different specimens' designs ( $\mathrm{C}-\mathrm{T}$ and $\mathrm{T}-\mathrm{T}$ ) were analysed using finite element analysis (FEA) through Abaqus software. The results of previous work ${ }^{17}$ were also considered, since they were on the basis of the first designs subjected to testing in this work. Modal analysis simulations were conducted to both the C-T and T-T specimens alone (i.e., with freefree boundary conditions), as well as with the specimens attached to the booster and horn as illustrated in figure 3. A dynamic modal analysis is also performed to the system's assembly, where a unit force harmonic excitation is applied at the resonant frequency determined in the modal analysis. This dynamic analysis will give a better understanding of the possible influence of modes shapes in the vicinity of the biaxial mode shapes under study.

Observing all the mode shapes of each specimen individually under free-free boundary conditions (figures 4 and 5 for specimens T-T and C-T respectively) there are a few mode shapes with similar displacements to the arm receiving the displacement from the horn. 
Theses modes are the ones most likely to have interference with the mode of interest but only if they have a relative frequency proximity to the working frequency $20 \pm 0.5 \mathrm{kHz}$ could his influence be relevant. These are the modes at $19,468 \mathrm{~Hz}$ for case T-T (2.7\% below the working frequency) and at 23,547 Hz for case C-T (17.7\% above the working frequency) represented in figure 4 and 5 respectively. Due to this similarities to the horn's movement these modes may have some influence on the deflection shape of the specimen even for a pure harmonic excitation at $20,000 \mathrm{~Hz}$, because of the stiffness and mass line contribution of mode shapes that are not within range but that are still close enough to have an influence on the target mode shape ${ }^{27}$.

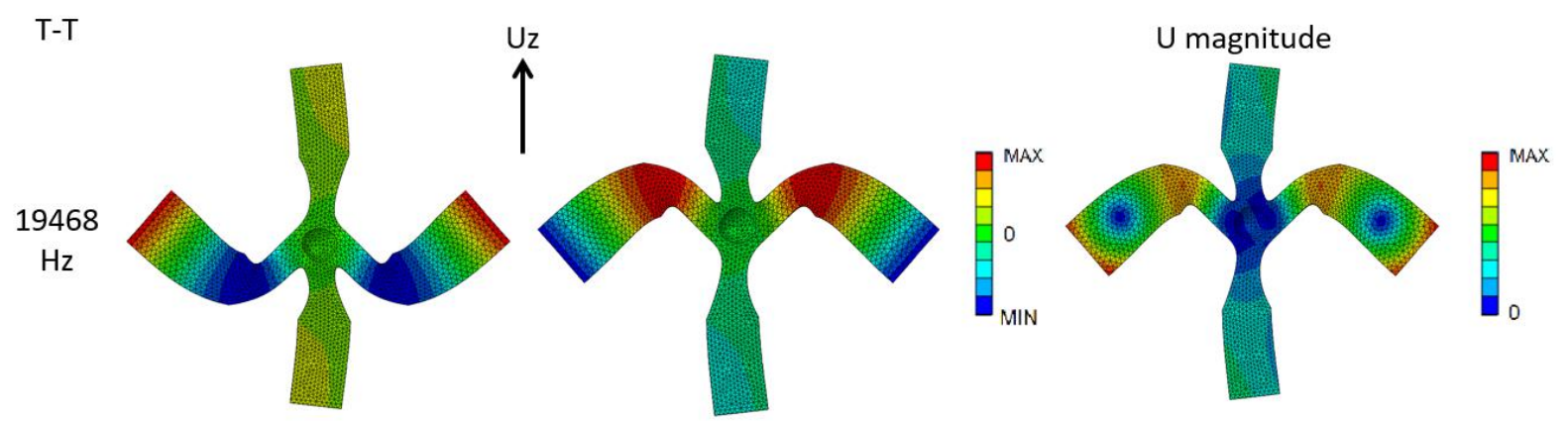

Fig. 4: Relevant resonant mode shape closest to the working frequency for the T-T specimen.
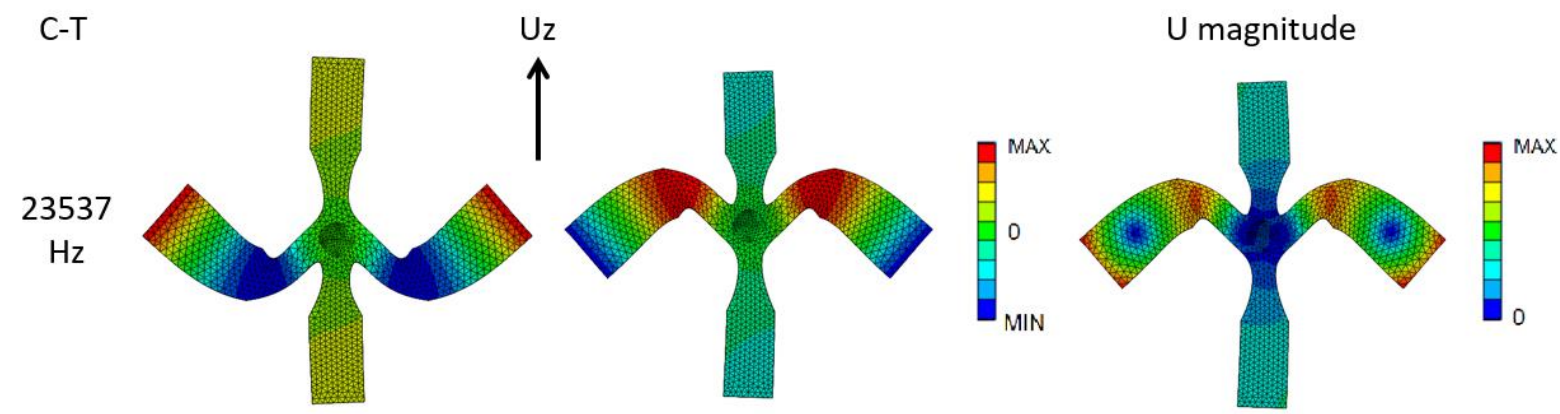

Fig. 5: Relevant resonant mode shape closest to the working frequency for the C-T specimen.

Afterwards a similar FEA modal analysis is made but with specimens attached to the horn and booster used in the ultrasonic machine. The obtained modal shapes are a combination of the specimen mode shapes with the horn and booster mode shapes. Thus, the modes presented in figure 2 , the modes of interest for both specimens, is represented in figure 6 and $7(A)$, and mode shapes of figures 4 and 5 are transformed and established with 
the horn and booster in figure 6 and 7 (B) for the T-T now at 19,442 Hz (2.7\% below the working frequency) and at $21,755 \mathrm{~Hz}$ for C-T (8.9\% above the working frequency) respectively.

(A)

19982

$\mathrm{Hz}$

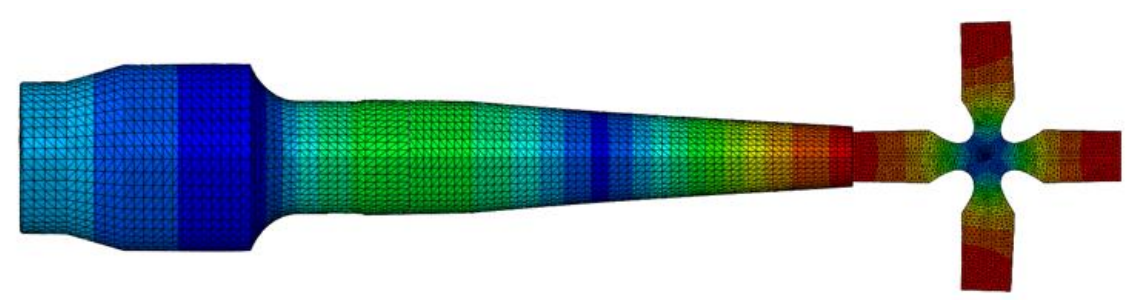

$U_{\text {mag }}$

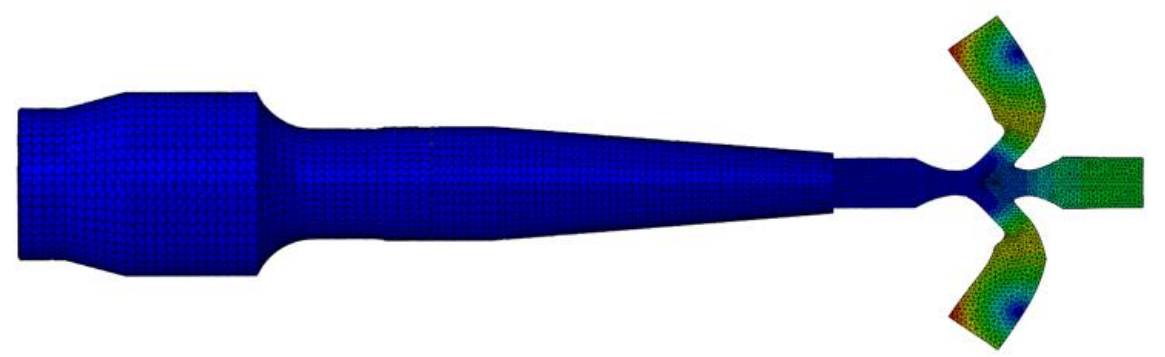

(B)

19442

$\mathrm{Hz}$

Fig. 6: Resonance mode shapes with the system components for the T-T specimen: (A) Mode of interest; (B) the most relevant one closest to the working frequency.

(A)

19977

$\mathrm{Hz}$

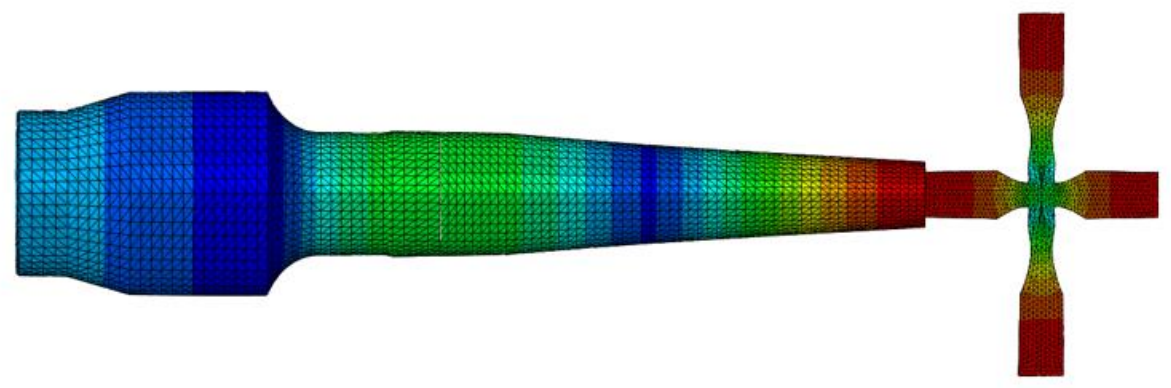

$U_{\text {mag }}$

$\operatorname{MAX}$

(B)

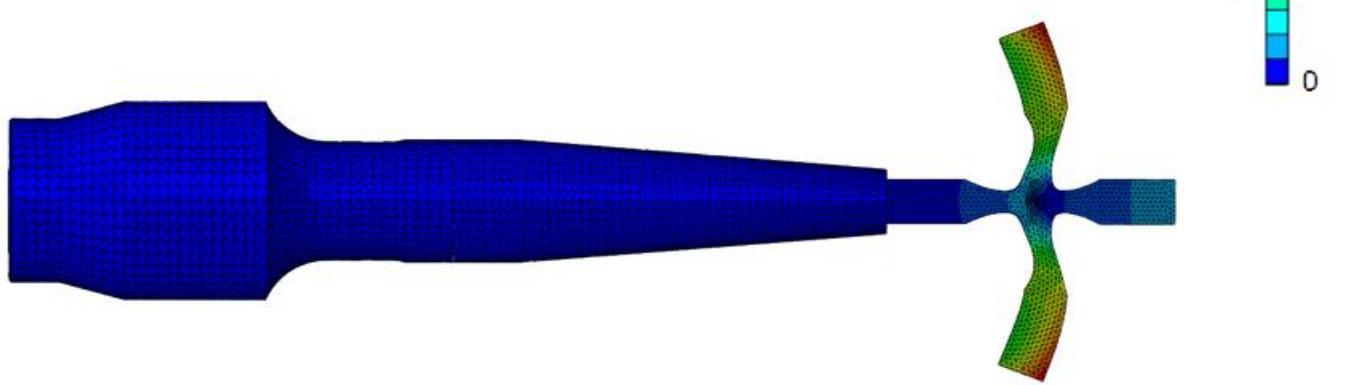

Fig. 7: Resonance mode shapes with the system components for the C-T specimen: $(A)$

Mode of interest; (B) the most relevant one closest to the working frequency.

All the represented mode shapes of figure 6 and 7 (B) of non-interest are excited with the longitudinal displacement of the booster and horn, just as the resonant mode of interest. The T-T specimen shape alone and with the attached horn and booster has the closest mode 
to the working frequency of $20 \mathrm{kHz}$. This means that the T-T shape will be under higher influence by the mode in figure 6.(B) when excited in the mode of interest.

Due to the proximity of the resonant mode of the T-T specimen presented in figure 6(B), it is important to understand how is the displacement distributed along the specimen, if there is indeed an influence of the non-interest mode. This analysis will be important not only to understand in what differs from the mode of interest but also how could it be measured and determined experimentally. The figure 8 shows in detail the displacement magnitude (A) and the vertical displacements with reduced scale (B) of a specimen obtained from a time iteration of a dynamic modal FEA analysis with the booster and horn in magnitude, . The reduction of figure 8.(B) scale is applied for a better comprehension of the changes in displacement along the specimen.

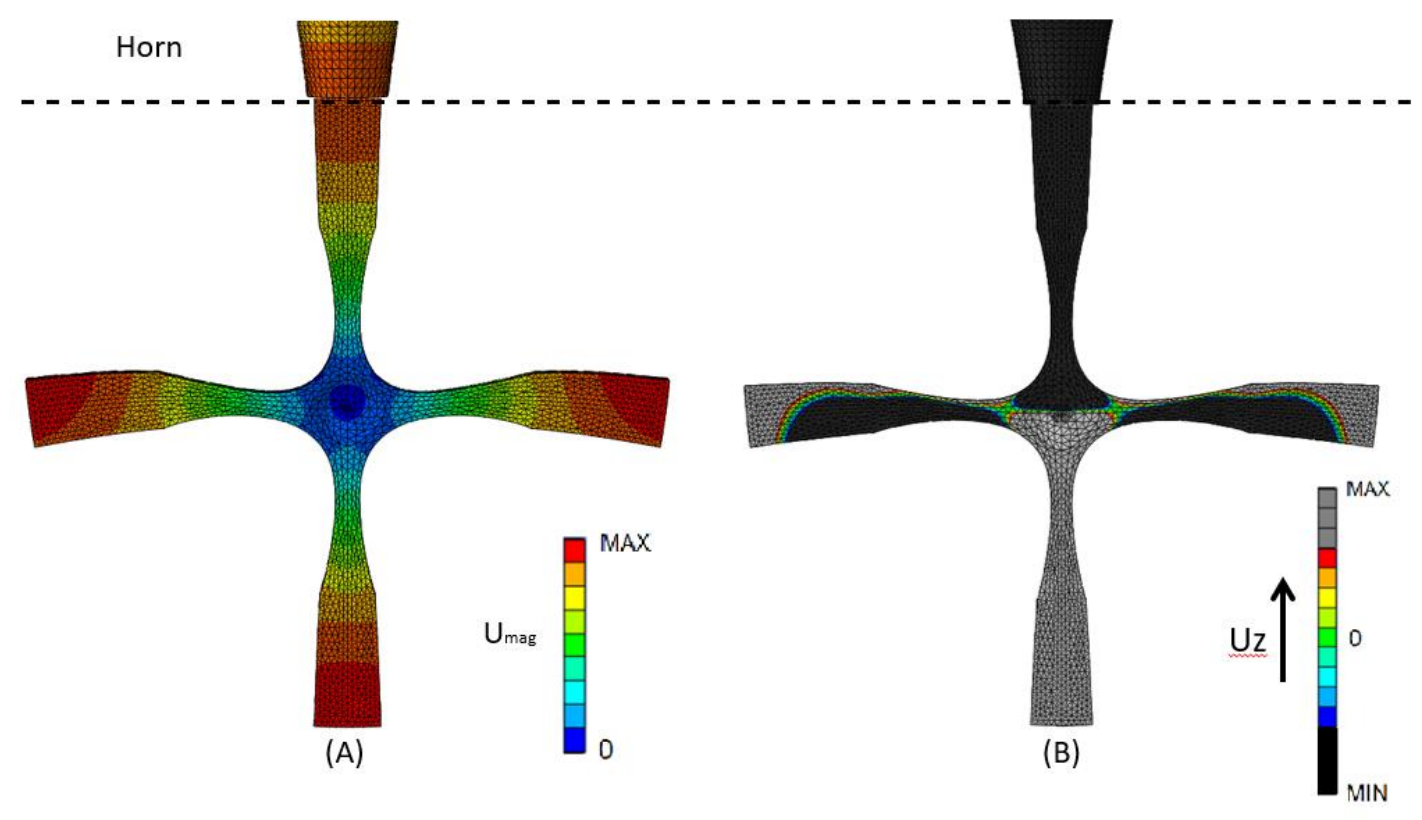

Fig. 8: FEA Dynamic modal results: (A) Displacement magnitude; (B) Longitudinal displacement with reduced scaling.

Through figure 8 the specimen shows in the dynamic modal FEA to have a combination of both modes of figure $6(A)$ and $(B)$. The horizontal arms have now a vertical node along its length. Thus, if the displacement is measured along the horizontal arm there will be a change in phase between opposite points of arm's length. 


\subsection{Ultrasonic testing for assessment of the specimens' designs}

Four specimens of each phase type of specimens were tested. The frequency analysis was firstly performed on all machined specimens showed that all C-T and T-T could be excited within the working frequency range of the transducer. Yet, this does not prove that the excited resonant mode shape of the cruciform specimens is the intended one or if it is occurring according the designed and determined by the FEA. Several tests were conducted using a laser doppler vibrometer to measure the displacement of several specimens at different coordinates and directions for afterwards correlate with the expected mode shape. All tests were conducted to several specimens of each geometry and with the same low power setting, with the exception of a more thorough measurement made to a T-T specimens' horizontal arms. Only a set of results is shown for each phase specimen due to the similarity and consistence of the laser results.

The Laser measurements at the extremities are shown in Figure 9 for each type of specimen. It is clear that, even though both types of cruciform specimens proved to have the correct and expected phase, only C-T showed to have similar amplitudes between both extremities, as intended. All current T-T specimens tested showed displacements at the extremities which are in-phase but with a considerable shift in amplitude, being systematically larger in the horizontal arms (Laser 2), around three times higher than in the vertical direction (Laser 1). The higher amplitude in the horizontal arms of T-T showed a similar amplitude to both extremities of C-T.

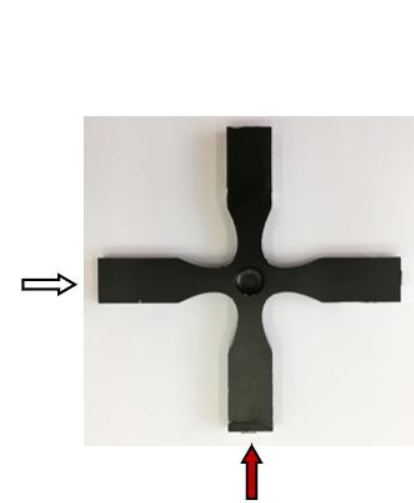

(A)

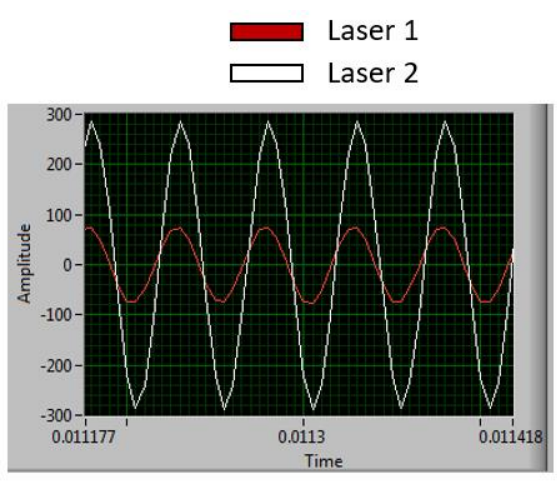

(B)

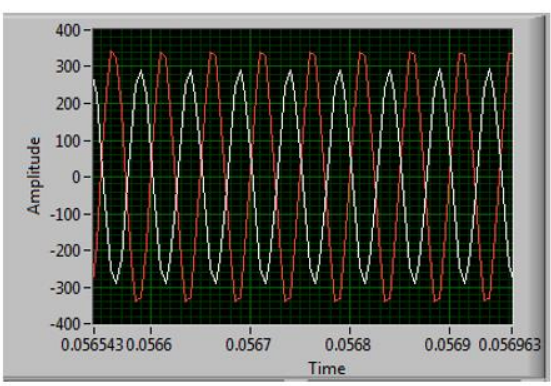

(C) 
Fig. 9: Displacement measurements of the specimens' extremities: $(A)$ representation of the measurement coordinates; (B) results for specimen type T-T; and (C) results for specimen type C-T.

After testing at the extremities, several vertical measurements were conducted along the horizontal arms. These after measurements were made to verify if there is vertical movement as indicated by the FEA. This movement is expected to be the reason for the higher amplitude acquired in the horizontal arms in the T-T specimen obtained in Figure 9.(B). If there was no vertical motion the lasers should show to be in phase and with low amplitude.

Firstly, a simple measurement with the lasers oriented as showed in Figure 10 for both specimens was conducted.

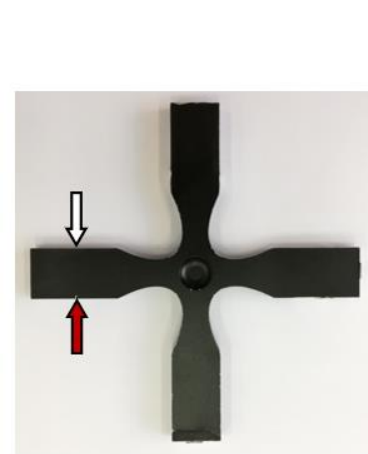

(A)

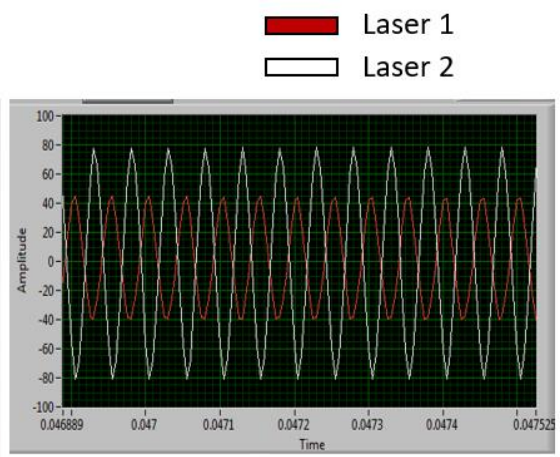

(B)

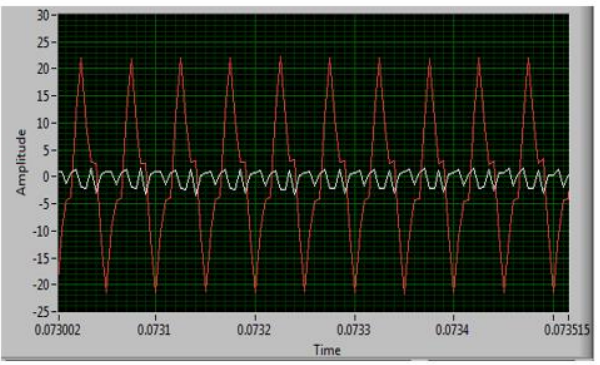

(C)

Fig. 10: Vertical displacement measurements of the specimens' horizontal arms: (A) representation of the measurement coordinates; (B) results for specimen type T-T; and (C) results for specimen type $\mathrm{C}-\mathrm{T}$.

From figure 10, the amplitude obtained when measuring transversely to the horizontal arms for the T-T specimens is higher than what is obtained for the C-T specimens, for the same testing conditions and using the same power setting. Moreover, for the C-T specimens the amplitude measurement showed to be around eight times lower than the highest value measured at the extremities, while for the T-T specimens it showed to be just around 2 times lower. Phase is also important, being observed that Laser 1 is out-of-phase with Laser 2, which is clearer for specimens T-T. This suggests a "flapping" condition of the horizontal arms, i.e., there is a combined translational and bending motion of the arms, as illustrated earlier in figures $7(B)$ and 8 , which supports the previous discussion based on the FEA models. 
It was also observed that even when the vertical laser measurements are on the same plane and colinear along the horizontal arms there is a difference in amplitude and phase in some locations of both specimens' types. Looking at the FEA results, the vertical movement varies along the arm's length in the underside of it and it actually changes direction at a certain point. Several measurements were made along the arm's length with one laser at the end of the opposite arm used as a reference. The results of these measurements are shown in figure 13 and were made with a power setting twice as high as in the previous experiments, so that the "flapping" behaviour of the horizontal arms already identified was highlighted.

(A)

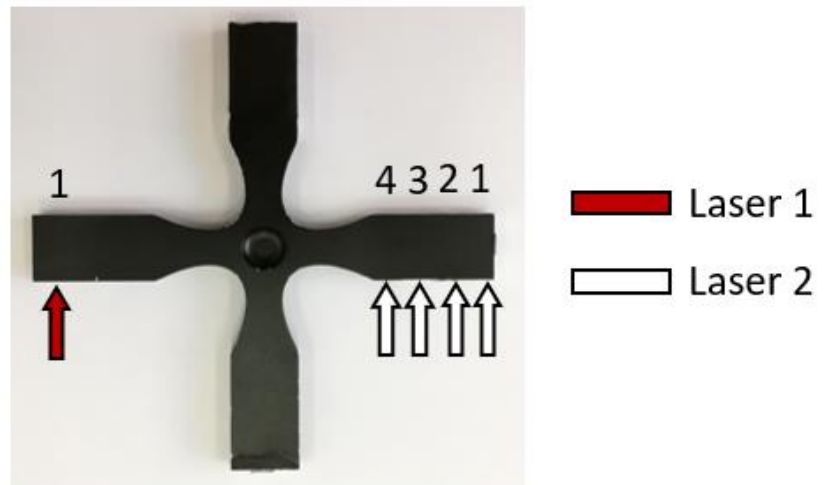

$1-1$

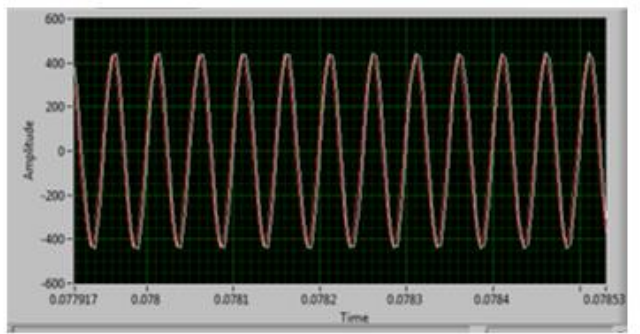

$1-3$

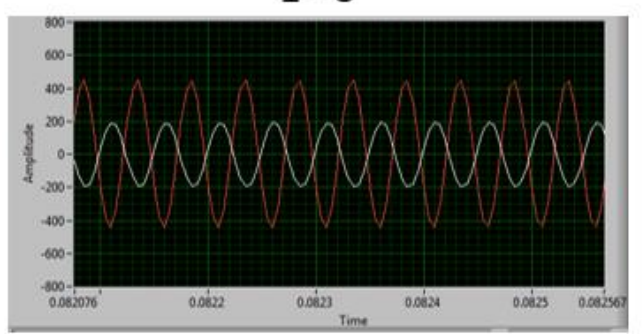

$1-2$

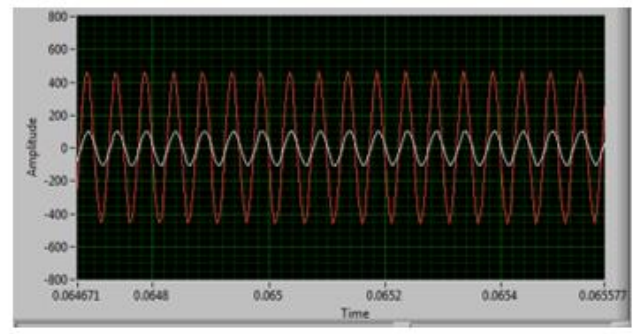

$1-4$

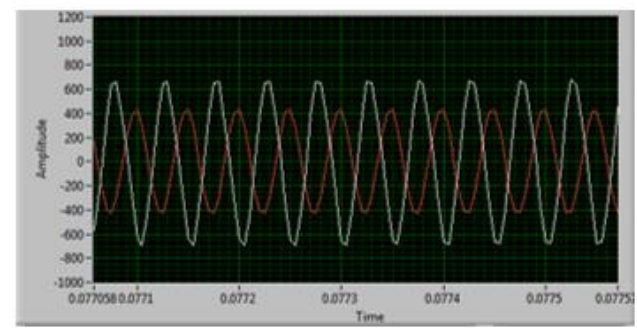

Fig. 11: Vertical displacement measurements along the of the specimens' horizontal arms:

(A) representation of the measurement coordinates; (B) results for specimen type T-T.

This experiment was only conducted with specimens $\mathrm{T}-\mathrm{T}$, since for specimens $\mathrm{C}-\mathrm{T}$ this "flapping" effect is much less pronounced, as observed from figure 10. The measurement point represented in figure 10 corresponds to point 2 in figure 11 . The change of phase along 
the arm's length, as observed in the FEA, was also proved comparing the 1-1 and 1-4 results. The highest amplitude was measured at point 4.

One final laser measurement was made to the vertical arms with the laser horizontally fixed (figure 12).

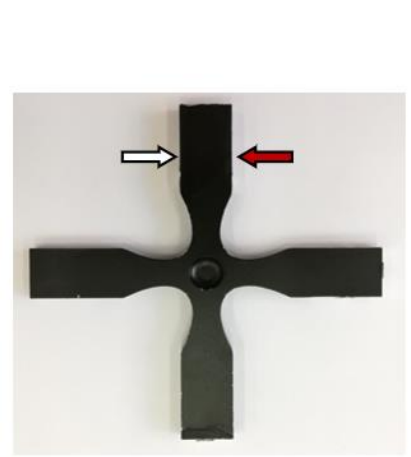

(A)

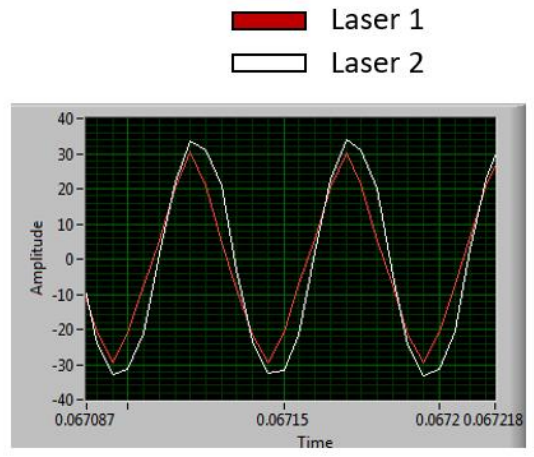

(B)

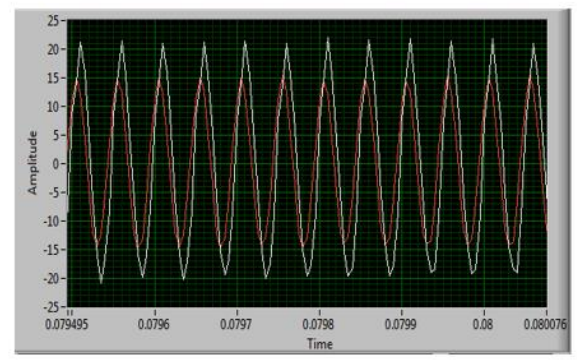

(C)

Fig. 12: Horizontal displacement measurements of the specimens' vertical arms: (A) representation of the measurement coordinates; (B) results for specimen type T-T; and (C) results for specimen type C-T.

Results show to be consistent with both the FEA models and the intended mode shapes for both specimen's types: both lasers showed to be in-phase and with a relatively low amplitude, especially when compared to the amplitude when measured in the axial direction which is about 10 to 15 times greater. This measurement of amplitude may be explained by the displacements caused by the elongation of the arms due to the Poisson coefficient of the tested material since both signals are in-phase. Being in phase means that at both points the displacement towards the laser is the same, meaning that the arm is elongating or compressing and not having a bending horizontal movement. The observed small difference in amplitude in figure 12.(B) may easily be due to a slight misalignment between both lasers, or inevitable geometrical and dimensional deviations (e.g., concentricity or flatness) of the manufactured parts in the system (from booster, through to horn and down to the specimen).

From the Laser measurements and numerical analysis, it was observed that the T-T specimens has a specific undesired vertical movement in the transversal arms, which motion resembles the "flapping" of a bird's wings, and a very low vertical displacement of the vertical extremity. There are a few reasons why this may be happening as discussed above. The most likely reason is the existence of a nearby resonant mode (at approximately $19.4 \mathrm{kHz}$, a $2.7 \%$ 
difference to the operating frequency), so the end result is an ODS (a combination of both modal response and forced vibration) rather than an "isolated" Mode Shape, thus altering the specimen's intended deflection shape. The difference in amplitude between the vertical arm and vertical movement is much lower experimentally than numerically estimated. This smaller difference could be related for the non-accounted geometrical deviations of the specimens that influence the frequency of all modes, which can translate in a much higher influence of the resonant mode of non-interest.

\subsection{Thermographic analysis}

In order to corroborate the conclusions above and get a better understanding on why specimens' type T-T are not operating as intended, a thermographic analysis was conducted. Thermal imaging of the T-T specimen shows that the greatest amount of heat is not being generated at the centre as intended, but near the connection to the horn, as shown in Figure 13.

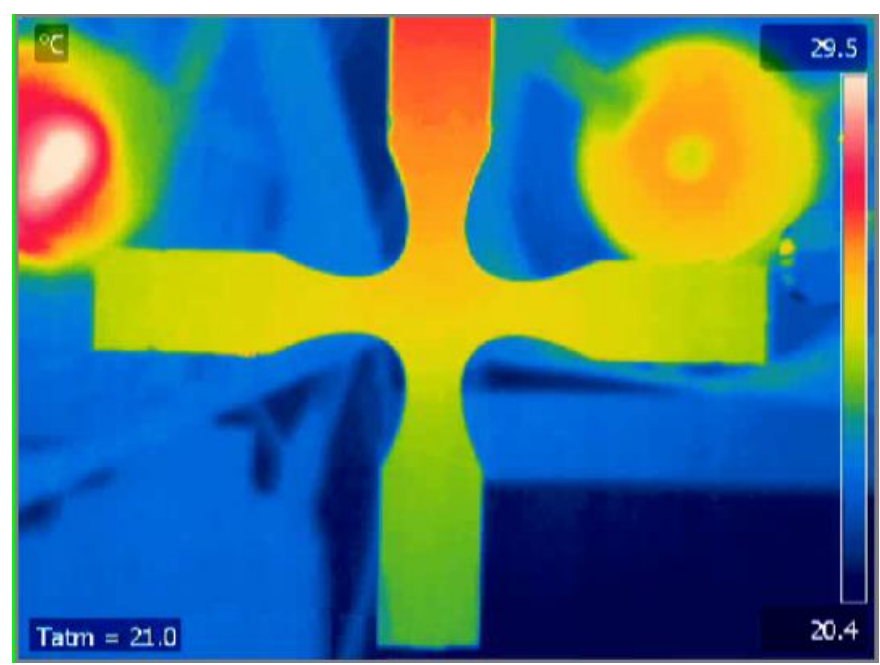

Fig. 13: Thermographic image of a T-T specimen under an ultrasonic fatigue test.

However, the C-T geometries proved to have acceptable performance. Thermal imaging also helps to reinforce the latter statement as Figure 14 shows a higher heat generation at the centre of a C-T specimen. 


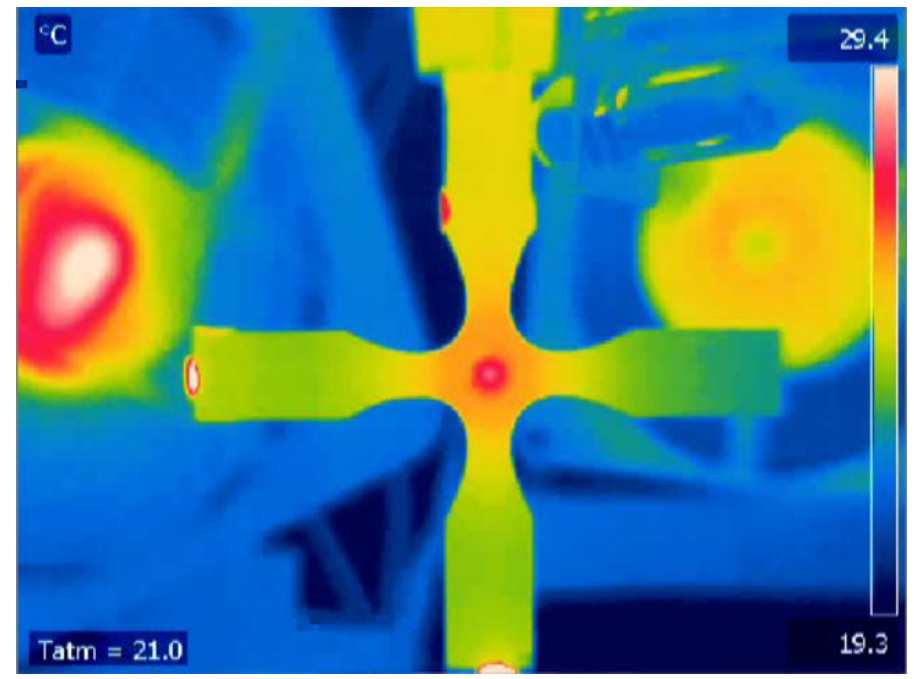

Fig. 14: Thermographic image of a C-T specimen under an ultrasonic fatigue test.

\subsection{Experimental testing to failure}

Knowing that the C-T specimen was being excited in the resonant mode of interest without significant influence from other mode shapes, a power-controlled test was performed until failure. In this test, a high enough constant power setting is applied to the specimen with temperature control and with displacement measurement at the free vertical arm. So, along the test a constant amplitude is measured and interruptions are made for cooling the specimen down for maintaining the highest heat generation region between 28 and 40 degrees. The chosen power was made empirically. If a specimen didn't break at a given power, a higher one was applied. For the determination of the applied stress a correlation between the displacement measured and the FEA analysis must be made as well as the usage of a strain gauge.

Throughout the test the number of cycles was counted from the waveform acquired by the Polytec Laser Doppler Vibrometer. After more than one million cycles (1E6) the specimen "lost" its resonance at around $20 \mathrm{kHz}$ due to the appearance of a fatigue crack at its centre (the stiffness decreased; hence the natural frequency of the entire system decreased as well until it reached the lower operating frequency of the machine at $19.5 \mathrm{kHz}$ ). In order to expose the fatigue crack surface for observation, the specimen was introduced to a hydraulic machine for a tensile test until complete failure. Figure 15 shows the crack before and after applying total failure to the specimen. 


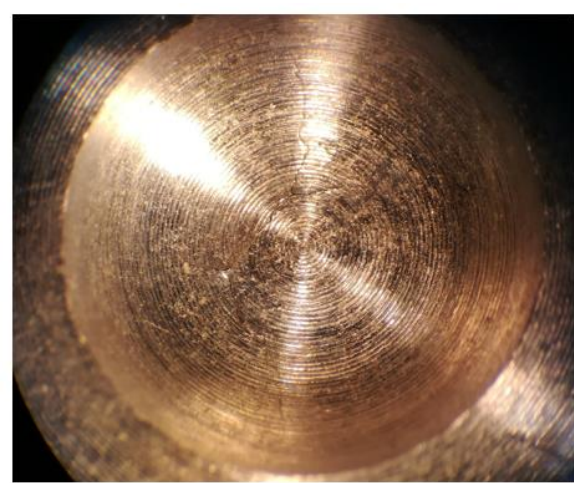

(A)

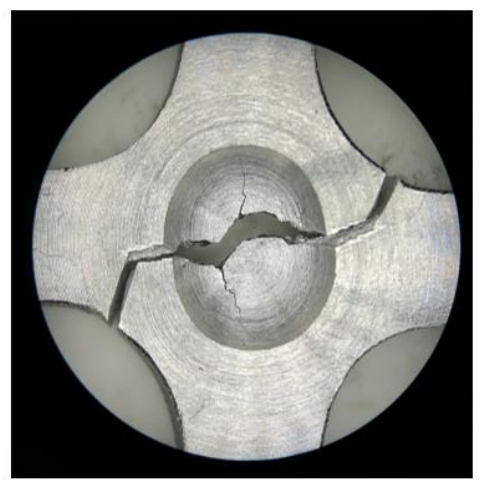

(B)

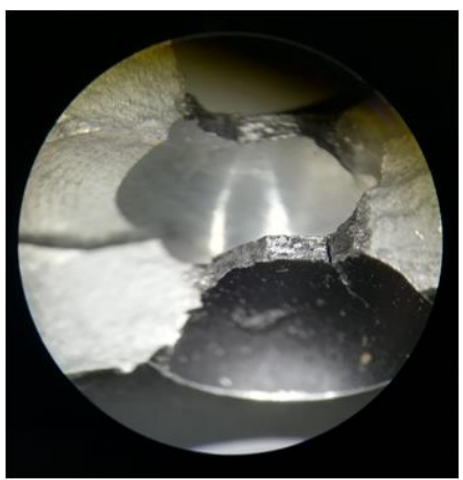

(C)

Fig. 15: (A) Amplification of the crack after ultrasonic testing (before facture); (B) C-T specimen after tensile test showing fracture paths; and $(\mathrm{C})$ microscopic image of the fatigue crack surface of the C-T specimen after fracture.

The created fracture showed three different types of crack surface zones. Two related to the induce and propagation of the fatigue crack with a more regular and smother surface and the third with a rough surface related to the rupture of the specimen made in the tensile machine.

The fatigue crack shows to have been initiated with \pm 50 -degree angle to the induced stresses around $0.5 \mathrm{~mm}$ from the centre. After fatigue crack initiation, the propagation bifurcated in two paths on both sides. The former \pm 50 -degree surface is similar to the latter ones but with a much shinier surface and with a more consistent direction as it can be seen in figure $17(B)$ and $(C)$. The fatigue crack fronts did not grow across the whole of the specimen's length due to the sudden increase of thickness and also due to the decrease in frequency which made the test come to a stop (due to limitations of the machine with regards to its operating bandwidth). The way the specimen broke in the tensile machine doesn't allow to see the surface of two of the four zones of fatigue propagation fractures created. The obtained angle in the crack initiation site seems adequate for the applied biaxial state considering that uniaxial tension/compression specimens have a crack surface normal to the specimen's length and the biaxiality ratio is $B=\frac{\sigma_{y}}{\sigma_{x}}=-1$ (for the C-T specimens). Thereby having an in-plane axial-axial with a $90^{\circ}$-degree relation with similar induced stresses in both directions, it is a fair assumption that the fracture angle should be in between the applied stresses. The $\pm 50^{\circ}$-degree angle of the fatigue crack initiation is shown in Figure 16 . This assumption is reinforced by numerical calculations results by the studies ${ }^{28,29}$ for the optimized 
specimen followed in this study, where four of six fatigue crack initiation criterions (Findley ${ }^{30}$; Brown-Miller ${ }^{31}$; Fatemi-Socie ${ }^{32}$; $\mathrm{Chu}^{33}$ ) predict that the fatigue crack initiation will be \pm 45 odegrees to the stress axis for the out-of-phase loading case (C-T specimen), considering AISI303 stainless steel ${ }^{28}$ and a typical aluminium ${ }^{29}$. It should also be mentioned that the study calculations consider the conventional stress inducing method for fatigue regimes below the VHCF. The fatigue crack criterion Findley and Fatemi-Socie mentioned show in ${ }^{34}$ to have better correlation to ductile materials such as the used aluminium. Such results strengths the obtained experimental results of the correct functioning of the C-T specimen.

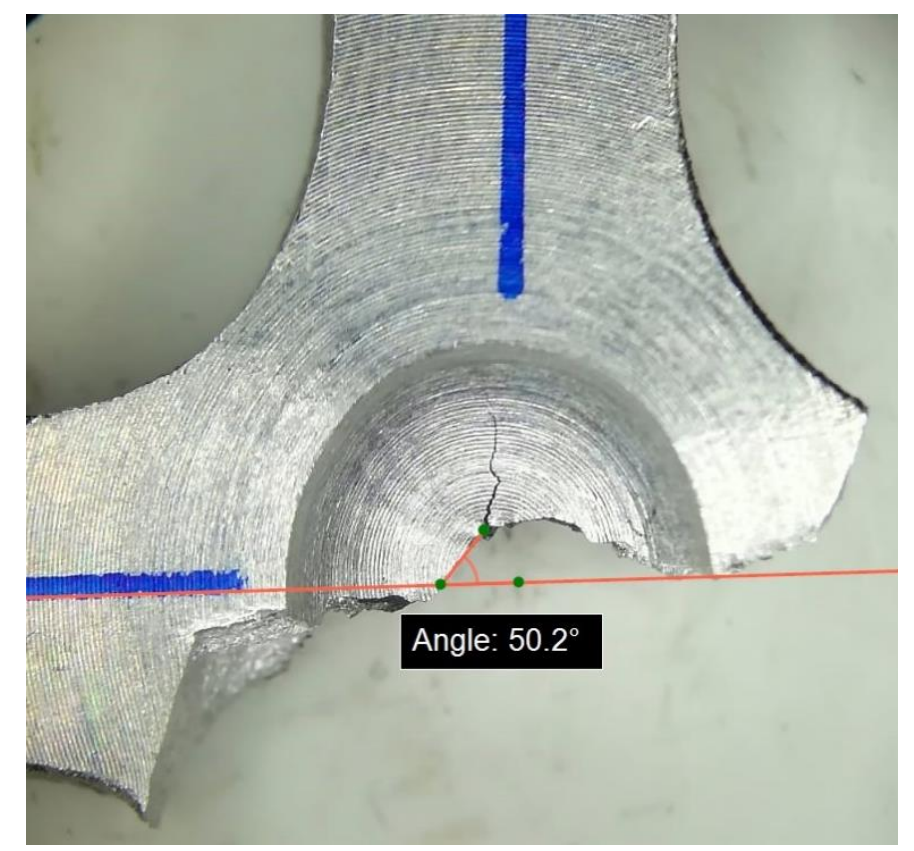

Fig. 16: Fatigue crack angle in relation to the arms in a C-T specimen.

\section{Conclusions}

In this work, the adaptation of cruciform specimens for ultrasonic VHCF as proposed in ${ }^{17}$ was thoroughly tested and analysed. Both FEA and experimental testing were performed, enabling several conclusions to be drawn.

Comparing numerical results between both geometries, it was observed that specimen T-T's behaviour when excited at $20 \mathrm{kHz}$ might suffer a considerable influence from at least one mode in the vicinity, even when excited with a pure harmonic excitation. On the other hand, C-T specimens, by having the other resonant modes sufficiently spaced away 
from the target resonant frequency, showed the intended dynamic behaviour when excited at the target frequency. The influence from modes in the vicinity was only possible to observe when the numerical models included the whole system composed by booster, horn and specimen. In such a case, and even if the ultrasonic fatigue testing machine used seeks to reproduce free vibration with all the parts and specimen vibrating at their own natural frequencies, there may be issues if each part does not have exactly the same resonant frequency, as what will be excited is an ODS rather than a mode shape. An ODS contains both forced and modal response components.

Comparing now both geometries, experimental results confirm some of the assumptions made on the FEA.

(1) The C-T specimen is able to vibrate with the intended mode shape, by having the extremities with the correct phase and approximate amplitudes. Furthermore, thermal imaging showed that the highest heat generation was at the centre of the specimen for specimen C-T. When exciting the system with a high enough power to induce a crack after more than a million cycles, the crack developed at $\pm 45^{\circ}$ between the horizontal and vertical axes, which is consistent with the assumption of numeric calculations of fatigue crack initiation criteria when the biaxiality ratio is $B=\frac{\sigma_{y}}{\sigma_{x}}=-1$.

(2) For the T-T specimen, a nearby (in terms of frequency) resonant mode appears to have a considerable influence on the results, making the mode of interest not being correctly induced. Also, this specimen did not show a higher heat generation at the centre and showed considerable differences in the amplitude of displacement between the extremities. It also showed considerable vertical motion of the horizontal arms.

All considered, the reason for the incorrect functioning of specimen T-T is shown to be related to the resonant mode shape found in the vicinity of the working frequency, having a much higher influence on specimen T-T than on specimen C-T, which was predicted numerically. From this fact, any small geometrical deviations in specimen T-T will have a greater effect in the final result. Having the T-T specimen a more complex geometry than the remaining system components, its frequencies suffer a higher influence from dimensional 
deviations that result from machining. This variation on frequency could impose a higher influence over the resonant mode of non-interest shown in figure 4 and consequently on the one in figure 6 (B). This higher influence cannot be created by altering the differences in frequencies of the resonant modes of the specimen in free-free boundary conditions alone, but also by considering system's components' frequencies. With higher differences between the system's and the specimen's frequencies, the contribute from the forced vibration component of the response is imposed over the modal component of the response, resulting in a complete system with a more significant ODS than predicted. This leads to a more pronounced displacement that resembles the 'flapping' of a bird, since it is a combination of an axial-axial with an axial-bending mode shape. Thus, the T-T specimen has to change to one where other resonant modes with similar anti-nodes have to be more spaced to the resonant mode of interest.

Finally, because of the intrinsic nature of the geometry of the specimen, only with the measured displacement in the extremities and the material's properties, it is quite difficult to calculate correctly the induced stresses at the centre of the specimen. There is a need to introduce a strain gauge in order to measure the strain and with it obtain the induced stress, which is left for further work.

\section{Acknowledgements}

This work was supported by FCT, through IDMEC, under LAETA, project UID/EMS/50022/2013. Financial support from Portuguese Fundação para a Ciência e Tecnologia (FCT) is acknowledged through Project PTDC/EMS-PRO/5760/2014.

\section{References}

1. Suryanarayana C. Experimental Techniques in Materials and Mechanics. CRC Press, ed; 2018. doi:10.1201/9781439895238

2. Fonte M, Li B, Reis L, Freitas M. Crankshaft failure analysis of a motor vehicle. Eng Fail Anal. 2013;35:147-152. doi:10.1016/j.engfailanal.2013.01.016

3. Bathias $C$. There is no infinite fatigue life in metallic materials. Fatigue Fract Eng Mater Struct. 1999;22:559-565. 
4. Bathias C, Paris PC. Gigacycle Fatigue in Mechanical Practice. Marcel Dekker, ed; 2005. doi:10.1201/9780203020609

5. Shimamura $\mathrm{Y}$, Narita $\mathrm{K}$, Ishii $\mathrm{H}$, et al. Fatigue properties of carburized alloy steel in very high cycle regime under torsional loading. Int J Fatigue. 2014;60:57-62. doi:10.1016/j.ijfatigue.2013.06.016

6. Wang QY, Lib T, Zenga XG. Gigacycle fatigue behavior of high strength aluminum alloys. Procedia Eng. 2010;2(1):65-70. doi:10.1016/j.proeng.2010.03.007

7. Brugger C, Palin-Luc T, Osmond P, Blanc M. Gigacycle fatigue behavior of a cast aluminum alloy under biaxial bending: experiments with a new piezoelectric fatigue testing device. Procedia Struct Integr. 2016;2:1179-1180. doi:10.1016/j.prostr.2016.06.150

8. Stanzl-Tschegg SE. Influence of material properties and testing frequency on VHCF and HCF lives of polycrystalline copper. Int J Fatigue. 2017;105:86-96. doi:10.1016/j.ijfatigue.2017.08.014

9. Bathias C. Piezoelectric fatigue testing machines and devices. Int J Fatigue. 2006;28(11):1438-1445. doi:10.1016/j.ijfatigue.2005.09.020

10. Pérez-Mora R, Palin-Luc T, Bathias C, Paris PC. Very high cycle fatigue of a high strength steel under sea water corrosion: A strong corrosion and mechanical damage coupling. Int J Fatigue. 2015;74:156-165. doi:10.1016/j.ijfatigue.2015.01.004

11. Amanov A, Cho IS, Kim DE, Pyun YS. Fretting wear and friction reduction of CP titanium and Ti-6Al-4V alloy by ultrasonic nanocrystalline surface modification. Surf Coatings Technol. 2012;207:135-142. doi:10.1016/j.surfcoat.2012.06.046

12. Xue HQ, Tao H, Montembault F, Wang QY, Bathias C. Development of a three-point bending fatigue testing methodology at $20 \mathrm{kHz}$ frequency. Int J Fatigue. 2007;29(911):2085-2093. doi:10.1016/j.ijfatigue.2007.03.018

13. Brugger C, Palin-Luc T, Osmond P, Blanc M. Gigacycle fatigue behavior of a cast aluminum alloy under biaxial bending: experiments with a new piezoelectric fatigue testing device. 21st Eur Conf Fract ECF21. 2016;2:96-100. doi:10.1016/j.prostr.2016.06.150

14. Mayer $\mathrm{H}$, Schuller R, Karr U, et al. Cyclic torsion very high cycle fatigue of VDSiCr spring steel at different load ratios. Int $J$ Fatigue. 2015;70:322-327. doi:10.1016/j.ijfatigue.2014.10.007

15. Vieira $M$, De Freitas $M$, Reis $L$, Ribeiro AMR, Da Fonte $M$. Development of a very high cycle fatigue (VHCF) multiaxial testing device. Frat ed Integrita Strutt. 2016;10(37):131137. doi:10.3221/IGF-ESIS.37.18

16. Costa P, Vieira M, Reis L, Ribeiro A, de Freitas M. New specimen and horn design for combined tension and torsion ultrasonic fatigue testing in the very high cycle fatigue regime. Int J Fatigue. 2017;103:248-257. doi:10.1016/j.ijfatigue.2017.05.022

17. Montalvão D, Wren A. Redesigning axial-axial (biaxial) cruciform specimens for very high cycle fatigue ultrasonic testing machines. Heliyon. 2017;3(11):e00466. 
doi:10.1016/j.heliyon.2017.e00466

18. Makris A, Vandenbergh T, Ramault C, Van Hemelrijck D, Lamkanfi E, Van Paepegem W. Shape optimisation of a biaxially loaded cruciform specimen. Polym Test. 2010;29(2):216-223. doi:10.1016/j.polymertesting.2009.11.004

19. Smits A, Van Hemelrijck D, Philippidis TP, Cardon A. Design of a cruciform specimen for biaxial testing of fibre reinforced composite laminates. Compos Sci Technol. 2006;66(78):964-975. doi:10.1016/j.compscitech.2005.08.011

20. Baptista R, Reis L, Guelho I, Freitas M, Madeira JFA. Design optimization of cruciform specimens for biaxial fatigue loading. Frat ed Integrita Struct. 2014;30:118-126. doi:10.3221/IGF-ESIS.30.16

21. Guelho I, Reis L, Freitas M, Li B, Madeira JFA, Cláudio RA. Optimization of Cruciform Specimen for Low Capacity Biaxial Testing Machine. 10th Int Conf Multiaxial Fatigue Fract. 2013.

22. Baptista R, Claudio RA, Reis L, Madeira JFA, Guelho I, Freitas M. Optimization of cruciform specimens for biaxial fatigue loading with direct multi search. Theor Appl Fract Mech. 2015;80:65-72. doi:10.1016/j.tafmec.2015.06.009

23. Freitas $\mathrm{M}$, Anes $\mathrm{V}$, Montalvao $\mathrm{D}$. Design and assembly of an ultrasonic fatigue testing machine. An Mecânica la Fract. 2011;1(28):335-340. http://uhra.herts.ac.uk/handle/2299/8189.

24. Cláudio RA, Reis L, Freitas M. Biaxial high-cycle fatigue life assessment of ductile aluminium cruciform specimens. Theor Appl Fract Mech. 2014;73:82-90. doi:10.1016/j.tafmec.2014.08.007

25. Lage $Y$, Ribeiro AMR, Montalvão D, Reis L, Freitas M. Automation in Strain and Temperature Control on VHCF with an Ultrasonic Testing Facility. Appl Autom Technol Fatigue Fract Test Anal. 2014:80-100. doi:10.1520/STP157120130079

26. Lage $Y$, Cachão $H$, Reis $L$, Fonte $M$, De Freitas $M$, Ribeiro A. A damage parameter for HCF and VHCF based on hysteretic damping. Int J Fatigue. 2014;62:2-9. doi:10.1016/j.ijfatigue.2013.10.010

27. Maia NMM, Silva JMM. Theoretical and Experimental Modal Analysis. (Maia NMM, Silva JMM, eds.). Research Studies Press LTD.

28. Baptista R, Cláudio RA, Reis L, Madeira JFA, Freitas M. Numerical study of fatigue crack initiation and propagation on optimally designed cruciform specimens. Procedia Struct Integr. 2016;1:98-105. doi:10.1016/j.prostr.2016.02.014

29. Baptista R, Cláudio RA, Reis L, Madeira JFA, Freitas M. Numerical study of in-plane biaxial fatigue crack growth with different phase shift angle loadings on optimal specimen geometries. Theor Appl Fract Mech. 2016;85:16-25. doi:10.1016/j.tafmec.2016.08.025

30. Findley WN. A Theory for the Effect of Mean Stress on Fatigue of Metals Under Combined Torsion and Axial Load or Bending. J Eng Ind. 1959;81(4):301-305. doi:10.1115/1.4008327 
31. Brown MW, Miller KJ. A Theory for Fatigue Failure under Multiaxial Stress-Strain Conditions. Proc Inst Mech Eng. 1973;187(1):745-755. doi:10.1243/PIME_PROC_1973_187_069_02

32. Fatemi A, Socie DF. A critical plane approach to multiaxial fatigue damage including out-of-phase loading. Fatigue Fract Eng Mater Struct. 1988;11(3):149-165. doi:10.1111/j.1460-2695.1988.tb01169.x

33. Chu C-C. Fatigue Damage Calculation Using the Critical Plane Approach. J Eng Mater Technol. 1995;117(1):41-49. doi:10.1115/1.2804370

34. Reis L, Li B, de Freitas M. Analytical and experimental studies on fatigue crack path under complex multi-axial loading. Fatigue Fract Eng Mater Struct. 2006;29(4):281289. doi:10.1111/j.1460-2695.2006.01001.x 